\title{
Comparison of Antimicrobial Efficacy of Cinnamon Bark Oil Incorporated and Probiotic Blend Incorporated Mucoadhesive Patch against Salivary Streptococcus mutans in Caries Active 7-10-year-old Children: An In Vivo Study
}

\author{
Henal A Gandhi ${ }^{1}$, KT Srilatha ${ }^{2}$, Seema Deshmukh ${ }^{3}$, MP Venkatesh ${ }^{4}$, Tanmoy Das ${ }^{5}$, Irfaan Sharieff ${ }^{6}$
}

\begin{abstract}
Introduction: Among the various plants studied, cinnamon has emerged as a potential herbal antimicrobial agent. Besides the medicinal plants, recently probiotics have also been recognized to affect cinnamon bark oil Streptococcus mutans (S. mutans) and other harmful oral and gut microflora.

Aim and objective: This placebo-controlled study aims to compare the antimicrobial potential of cinnamon bark oil incorporated and probiotic blend [Lactobacillus plantarum (TSP-Lp1), and Lactobacillus rhamnosus (TSP-Lrh1)] incorporated mucoadhesive patch against salivary S. mutans in caries active 7-10-year-old children.

Design: It was a double-blinded placebo-controlled study with $n=60$. They were randomly allotted into three groups-Group I: Cinnamon patch, group II: probiotic patch, and group III: control patch (placebo) with $n=20$ in each group.

Materials and methods: The study was carried out in three phases. In the first phase, the minimal inhibitory concentration (MIC) of cinnamon bark oil was determined against S. mutans followed by the formulation of cinnamon and probiotic patches. After a washout period of 2 weeks and a collection of baseline saliva samples, these patches were tested on the subjects from respective groups for 14 days with twice a day placement protocol. On the 15th day, saliva samples were collected and cultured, CFU/mL of the saliva of S. mutans for each subject was recorded and compared with baseline samples. Feedback in the form of a questionnaire was obtained from the patients.

Statistical analysis: Descriptive statistics, paired $t$-test for intragroup comparison, unpaired $t$-test for intergroup comparison, analysis of variance (ANOVA) for intergroup comparison, and post hoc Scheffe's.

Results: The results showed that both cinnamon patch and probiotic patch were comparable to each other in terms of their anti-S. mutans activity. The intragroup comparison of the $\mathrm{CFU} / \mathrm{mL}$ count showed a highly significant reduction from baseline to post-intervention for both the groups $(p=0.001)$.

Conclusion: Both cinnamon and probiotic blend have a strong antimicrobial property owing to their ability to cause significant reduction in salivary S. mutans and both the patches showed good patient acceptance.
\end{abstract}

Keywords: Dental caries, Mucoadhesive patch, Probiotic, Streptococcus, Streptococcus mutans.

International Journal of Clinical Pediatric Dentistry (2020): 10.5005/jp-journals-10005-1818

\section{INTRODUCTION}

Dental caries is one of the most common diseases in the worldsecond only to the common cold. ${ }^{1}$ The notion that dental caries in animals is an infectious transmissible disease was first demonstrated by Keyes. ${ }^{2}$ Dental caries can be prevented by the maintenance of proper oral hygiene with the use of oral care products like toothpaste, toothbrush, and even mouthwashes with antimicrobial and anti-cariogenic properties. However, the incidence of adverse effects from the use of these chemical products has brought about an inclination toward the use of natural remedies for achieving the same. This has led to research and development in the area of functional foods having a potentially positive effect on health beyond basic nutrition. The concept of functional food was introduced long back by Hippocrates with the motto being "let food be your medicine". ${ }^{3}$ Moreover, for thousands of years, medicinal plants have been used in many parts of the world as traditional treatments to cure a multitude of ailments including toothache. Among the various plants studied, Cinnamomum zeylanicum Blume (cinnamon) ${ }^{4,5}$

\footnotetext{
${ }^{1-3}$ Department of Paediatric and Preventive Dentistry, JSS Dental College and Hospital, Mysuru, Karnataka, India

${ }^{4,5}$ Department of Pharmaceutics, JSS College of Pharmacy, Mysuru, Karnataka, India

${ }^{6}$ Triphase Pharmaceuticals Pvt Ltd, Mysuru, Karnataka, India

Corresponding Author: Henal A Gandhi, Department of Paediatric and Preventive Dentistry, JSS Dental College and Hospital, Mysuru, Karnataka, India, e-mail: doc.henal@gmail.com

How to cite this article: Gandhi HA, Srilatha KT, Deshmukh S, et al. Comparison of Antimicrobial Efficacy of Cinnamon Bark Oil Incorporated and Probiotic Blend Incorporated Mucoadhesive Patch against Salivary Streptococcus mutans in Caries Active 7-10-year-old Children: An In Vivo Study. Int J Clin Pediatr Dent 2020;13(5):543-550.

Source of support: Nil

Conflict of interest: None
}

has emerged as a potential herbal antimicrobial agent. The bark of various cinnamon species is one of the most important and popular spices used worldwide not only for cooking but 
also in traditional and modern medicines. Cinnamon bark oil can inhibit amino acid decarboxylase activity in various oral pathogenic bacteria due to the presence of an active ingredient cinnamaldehyde (highly electronegative), an aromatic aldehyde. ${ }^{6}$ Cinnamon bark oil also contains benzoic acid, benzaldehyde, and cinnamic acid, which too have been recognized to have antimicrobial properties. Also, cinnamon bark oil contains $4.7 \%$ eugenol, which depending upon the concentration used is known to be either bactericidal or bacteriostatic agent. An essential oil from cinnamon bark also contains cinnamyl acetate (8.7\%), which increases the activity of the parent compound. ${ }^{7}$ Besides the medicinal plants, recently probiotics have also been recognized to affect Streptococcus mutans (S. mutans) and other harmful oral and gut microflora. The term probiotics was introduced by Lilley and Stillwell in $1965 .{ }^{8}$ Probiotics have been used in combating various diseases, such as, gastrointestinal infections, cancer prevention, constipation, irritable bowel syndrome, periodontal diseases, and dental caries. ${ }^{9}$ The mechanisms of action of probiotics in the human body include normalization of the microbiota, modulation of an immune response, and metabolic effects. ${ }^{9}$ Probiotics in the oral cavity have been used to replace cariogenic organisms like streptococci and Lactobacillus species with strains of bacteria that are not cariogenic. ${ }^{10}$ Many clinical studies have confirmed that probiotic lactobacilli can reduce the counts of salivary $S$. mutans after the ingestion of Lactobacillus rhamnosus-GG, $L$. reuteri, L. plantarum, and lactobacilli mix. ${ }^{9}$ Studies have shown that probiotics are as effective as chlorhexidine and safer than chlorhexidine. ${ }^{11}$ Hence, in the proposed study, probiotics were used as a safer alternative to chlorhexidine in children.

A mucoadhesive patch incorporated with anti-cariogenic and antibacterial agents may help in slowly releasing the drug in the oral cavity where there is a constant circulation of the drug in the oral cavity through saliva ${ }^{12}$ and hence it has a potential to be used as an alternative to mouthwash especially in the pediatric age group.

There is no documented literature comparing the efficacy of cinnamon bark oil and probiotic incorporated mucoadhesive patch against $S$. mutans, hence this placebo-controlled study was taken up to test the hypothesis.

\section{Materials and Methods}

The present study was carried out at the Department of Pedodontics and Preventive Dentistry, JSS Dental College and Hospital, Mysuru. The participants comprised of children aged 7-10 years were selected from St. Matthias Primary School, Bannimantap, Mysuru. The nature of the study, its duration, and objectives were clearly described and explained to the authorities.

Before the start of the study, ethical clearance was obtained from the Institutional Ethical Committee, and written informed consent and assent was obtained from all the parents and the children participating in the study, and the study was carried out under the Helsinki Declaration of 1975, as revised in 2000.

\section{Study Design}

Placebo-controlled double-blinded randomized clinical trial.

\section{Sample Size}

Using mean and standard deviation from earlier studies with the power of study $80 \%$ and a confidence interval of $95 \%$, the sample size estimated was 17. Anticipating the loss of study subjects to follow-up, the sample size chosen was a total of 60 subjects with 20 subjects in each of the three groups.

$$
N=\frac{\left(Z_{\alpha / 2}+Z_{\beta}\right)^{2}\left(\sigma_{1}^{2}+\sigma_{2}^{2}\right)}{L^{2}}
$$

$$
\begin{aligned}
& N=\text { sample size } \\
& \alpha \text { and } \beta=\text { constants } \\
& \sigma_{1}=\text { SD of group I } \\
& Z=\text { the power of the study }(80 \%) \\
& \sigma_{2}=\text { SD of group II } \\
& L=\text { Difference of means }
\end{aligned}
$$

\section{Sampling Methodology}

From a pediatric population from 7 to 10 years of age, 60 children were selected based on the predetermined inclusion criteria and exclusion criteria. The subjects were screened and selected from St. Matthias Primary School, Bannimantap, Mysuru. The subjects were further divided into three groups-cinnamon patch group (group I), probiotic patch group (group II), and control group (group III) by the simple random sampling (lottery method). Healthy children in the age group of 7-10 years who have voluntarily signed the informed assent and consent with deft/DMFT score 3 and $<5$ and Frankel's behavior rating of "positive" and "definitely positive" were included in the study whereas children with oral or systemic diseases and medically compromising conditions with history of hypersensitivity reactions and under long-term antibiotic therapy were excluded. Children with acute symptoms requiring immediate dental treatment with deep dental caries or grossly decayed teeth were also excluded from the study (Flowchart 1).

\section{Methods}

The study was carried out in three phases.

Phase 1: Antimicrobial testing and minimal inhibitory concentration (MIC) determination-The antibacterial effect of various concentrations $(2.5,5,10$, and $20 \mu \mathrm{L} / \mathrm{mL})$ of the cinnamon bark oil against $S$. mutans was determined using the broth microdilution method. The inoculums of test strains were adjusted to an optical density of 0.1 ( 0.5 McFarland standard) which corresponds to 1.5 $\times 10^{8} \mathrm{CFU} / \mathrm{mL}$ by diluting it with sterile brain heart infusion $(\mathrm{BHI})$ broth using a spectrophotometer. One hundred microliters of each test concentration and bacterial inoculum were added into each of the wells of the 96-well tissue culture plate in an orderly predecided manner. After 24 hours of incubation under anaerobic conditions, the antibacterial activity was recorded using visual confirmation and reading of absorbance using a multimode plate reader (Tables 1 and 2). Minimal inhibitory concentration of cinnamon bark oil $(76.8 \%$ cinnamaldehyde-active ingredient, Cinnamon Vogue, Las Vegas, Nevada) was estimated to be $20 \mu \mathrm{L} / \mathrm{mL}$ (Fig. 1). The strength of the probiotic blend of $L$. plantarum (TSP-LP1) and $L$. rhamnosus (TSP-Lrh1) (Triphase Pharmaceuticals Pvt. Ltd., Mysuru) was determined taking into consideration the literature available on the use of safe and effective strength of probiotic strains in children from a dental point of view which ranges from $10^{5}$ to $10^{9}$ with $10^{9}$

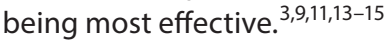

Phase 2: Formulation of cinnamon bark oil incorporated, probiotic blend [L. plantarum (TSP-Lp1) and L. rhamnosus (TSPLrh1)] incorporated and placebo mucoadhesive patch-The mucoadhesive patches were formulated at the Department of Pharmaceutics at JSS College of Pharmacy, Mysuru and were 
Flowchart 1: Flow diagram showing methodology of the study

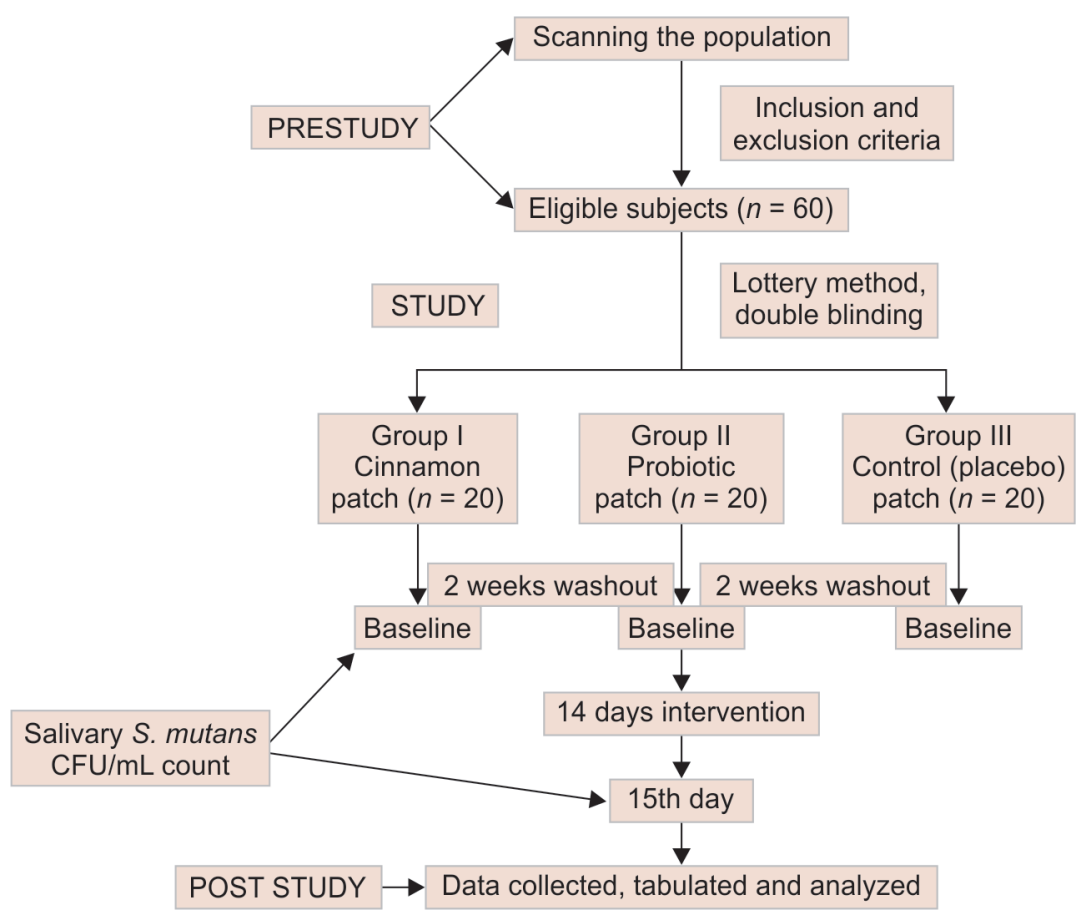

Table 1: Mean optical density (OD) values of the different concentrations of cinnamon bark oil against Streptococcus mutans

\begin{tabular}{|c|c|c|c|c|c|c|c|}
\hline \multirow[b]{2}{*}{ Bacterial broth } & \multirow[b]{2}{*}{ Blank DMSO } & \multirow{2}{*}{$\begin{array}{l}\text { Blank broth } \\
\text { (negative } \\
\text { control) }\end{array}$} & \multirow{2}{*}{$\begin{array}{l}0.2 \% \text { CHX with } \\
\text { bacterial broth } \\
\text { (positive control) }\end{array}$} & \multicolumn{4}{|c|}{ Test concentrations of cinnamon oil } \\
\hline & & & & $2.5 \mu \mathrm{L} / \mathrm{mL}$ & $5 \mu \mathrm{L} / \mathrm{mL}$ & $10 \mu \mathrm{L} / \mathrm{mL}$ & $20 \mu \mathrm{L} / \mathrm{mL}$ \\
\hline 0.34 & 0.30 & 0.08 & 0.16 & 0.23 & 0.23 & 0.20 & 0.16 \\
\hline
\end{tabular}

Table 2: Percentage reduction in the optical density (OD) values of the different concentrations of cinnamon bark oil against Streptococcus mutans

\begin{tabular}{|c|c|c|c|c|}
\hline $\begin{array}{l}\text { Concen- } \\
\text { tration of } \\
\text { cinnamon } \\
\text { bark oil }\end{array}$ & $2.5 \mu \mathrm{L} / \mathrm{mL}$ & $5 \mu \mathrm{L} / \mathrm{mL}$ & $10 \mu \mathrm{L} / \mathrm{mL}$ & $20 \mu \mathrm{L} / \mathrm{mL}$ \\
\hline $\begin{array}{l}\text { Percentage } \\
\text { reduction in } \\
\text { OD values }\end{array}$ & 30.47 & 31.96 & 39.78 & 51.20 \\
\hline
\end{tabular}

optimized for various formulation ingredients before making the final batches of mucoadhesive patches. Mucoadhesive patches were prepared using the solvent casting technique. ${ }^{16}$ All the materials used for the patch preparation are approved by the FDA and come under the category of GRAS (Generally regarded as safe). ${ }^{17}$ Carbopol 934P and Hydroxypropyl methylcellulose (HPMC) K15LV were used as the mucoadhesive polymers and polyethylene glycol (PEG) 4000 was used as the plasticizer. Stevia was used as a sweetening agent. $1.5 \mathrm{~L}$ of the cinnamon bark oil ( $20 \mu \mathrm{L}$ per patch) and $10 \mathrm{mg}$ of the probiotic blend [ 5 billion of L. plantarum (TSP-Lp1) and 5 billion of L. rhamnosus (TSP-Lrh1)] was required for a batch of 75 patches. Mucoadhesive patches were cut in $1 \times 1 \mathrm{~cm}$ size and evaluated for thickness uniformity, weight uniformity, and $\mathrm{Ph}$.

Phase 3: Clinical trial-From caries active pediatric population of 7-10 years of age, 60 children were selected based on the predetermined inclusion criteria and exclusion criteria. They were

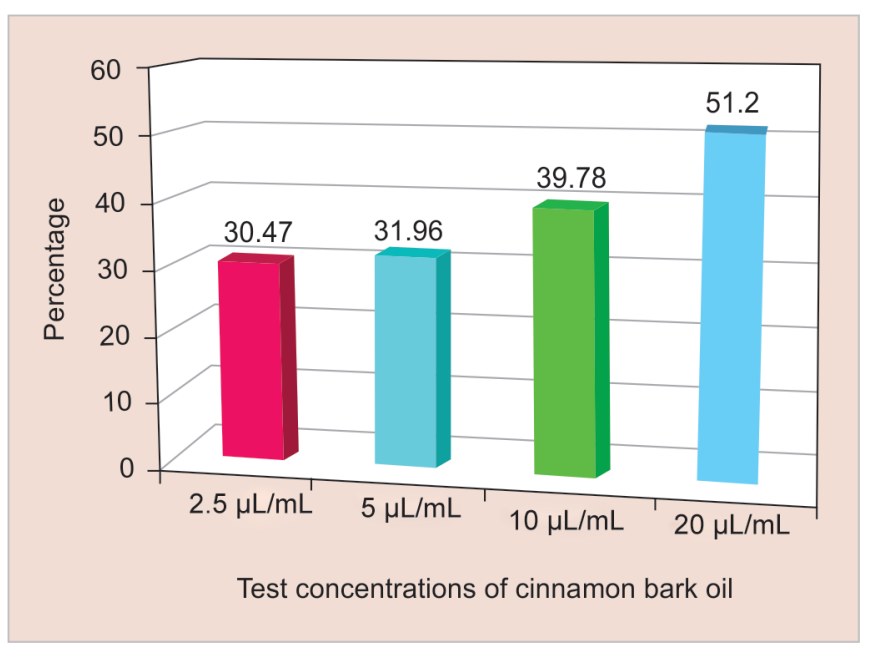

Fig. 1: Percentage reduction in the optical density values of the different concentrations of cinnamon bark oil against Streptococcus mutans

randomly allotted into three groups-Group I: cinnamon patch, group II: probiotic patch, and group III: control patch (placebo) (Fig. 2). A washout period of 2 weeks was observed. The clinical study commenced with the recording of case history followed by the collection of baseline saliva samples. Patches were placed on the palatal slope (Fig. 3) every day 1 hour post breakfast and they were also given patches in a sterile sealed pouch to be placed 1 hour post-dinner under parent's supervision for 14 days ${ }^{9}$ followed 


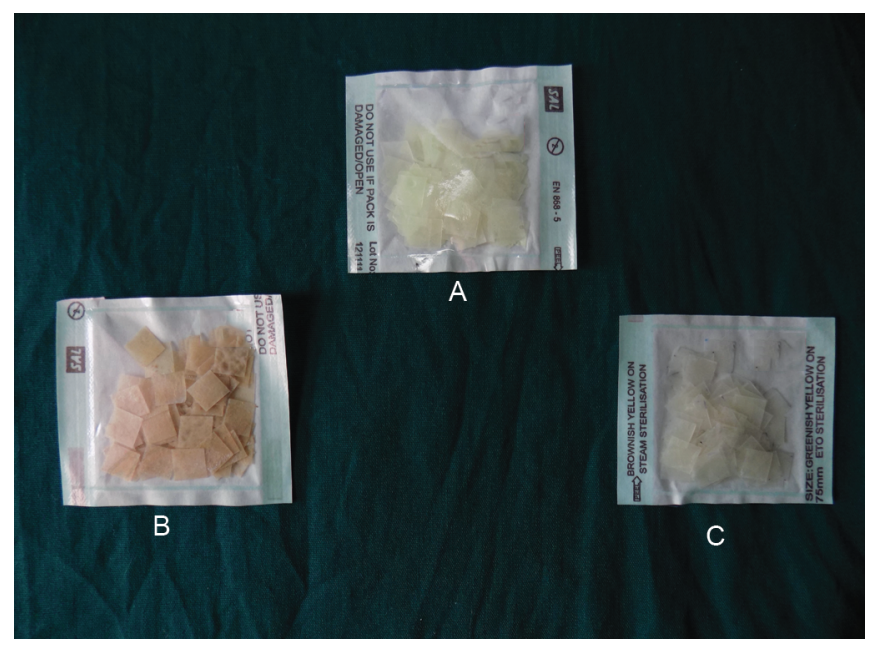

Fig. 2: (A) Cinnamon bark oil incorporated; (B) Probiotic blend incorporated; (C) Control/placebo patch

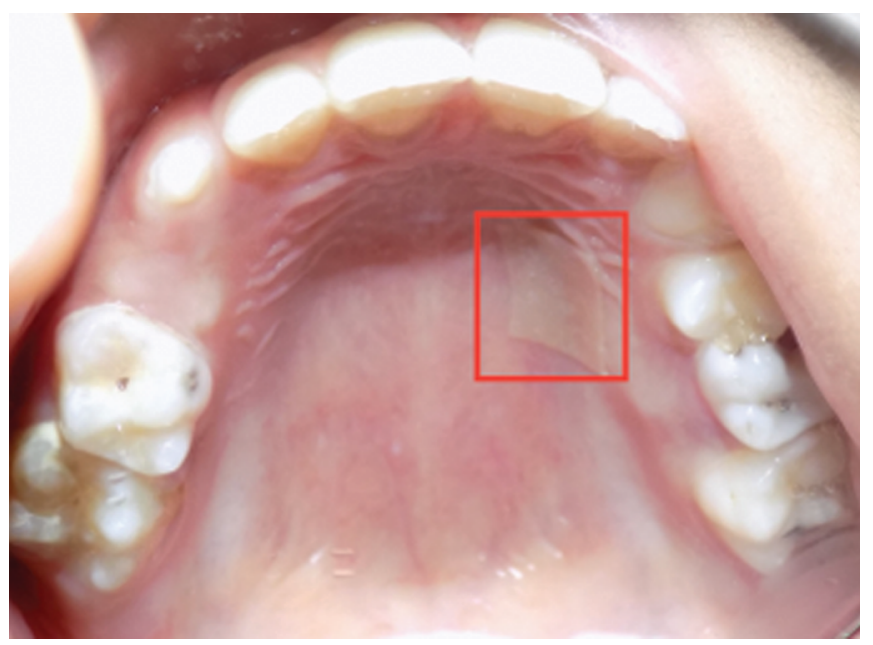

Fig. 3: Position of patch placement

Table 3: Descriptive statistics for colony-forming units per $\mathrm{mL}(\mathrm{CFU} / \mathrm{mL})$

\begin{tabular}{|c|c|c|c|c|c|c|c|}
\hline Group & $N$ & $\begin{array}{l}\text { Mean of baseline } \pm \\
\text { SD }(C F U / m L)\end{array}$ & Minimum & Maximum & $\begin{array}{l}\text { Mean of post-intervention } \pm \\
S D(C F U / m L)\end{array}$ & Minimum & Maximum \\
\hline $\begin{array}{l}\text { Cinnamon patch } \\
\text { group }\end{array}$ & 0 & $39,650 \pm 20,606.99$ & 7,800 & 74,400 & $416.5 \pm 241.30$ & 30 & 800 \\
\hline Probiotic group & 0 & $37,113 \pm 21,151.80$ & 8,400 & 78,400 & $602 \pm 387.16$ & 100 & 1,600 \\
\hline Control group & 0 & $33,971 \pm 21,328.34$ & 7,800 & 76,000 & $19465 \pm 11,603.01$ & 3,200 & 44,000 \\
\hline
\end{tabular}

by saliva sample collection on the 15th day. A record was maintained for all subjects to ensure the daily placement of mucoadhesive patches. Any adverse effects experienced by subjects demanded immediate notification from the parents and was recorded. Salivary S. mutans count was checked at baseline and post-intervention and compared for all three groups.

\section{Results}

The results showed that both cinnamon patch and probiotic patch were comparable to each other in terms of their anti-S. mutans activity (Table 3 and Fig. 4). The intragroup comparison of CFU/ $\mathrm{mL}$ count showed a highly significant reduction from baseline to post-intervention for all three groups (Table 4). One-way analysis of variance (ANOVA) revealed a significant difference in mean CFU counts of groups, i.e., cinnamon patch group (group I), probiotic patch group (group II), and control patch group (group III). F value of 53.30 was found to be significant at $p=0.001$. Mean CFU count at post-intervention was $416.5,602$, and $19,465 \mathrm{CFU} / \mathrm{mL}$ for group I, group II, and group III, respectively (Table 5). Furthermore, Scheffe's post hoc test revealed that there was no significant mean difference between the cinnamon patch group (group I) and the probiotic patch group (group II). However, there was a significant mean difference between the cinnamon patch group (group I) and control patch group (group III) and probiotic patch group (group II) and control patch group (group III) with less CFU $/ \mathrm{mL}$ reduction seen in control patch group ( $p=0.05$ ) (Fig. 5). A questionnaire was used to assess patient compliance in terms of the presence of adverse effects if any like displeasure in taste, alterations in the breath, teeth staining, nausea, and any other symptoms. Ten percent of the subjects in the probiotic patch group experienced

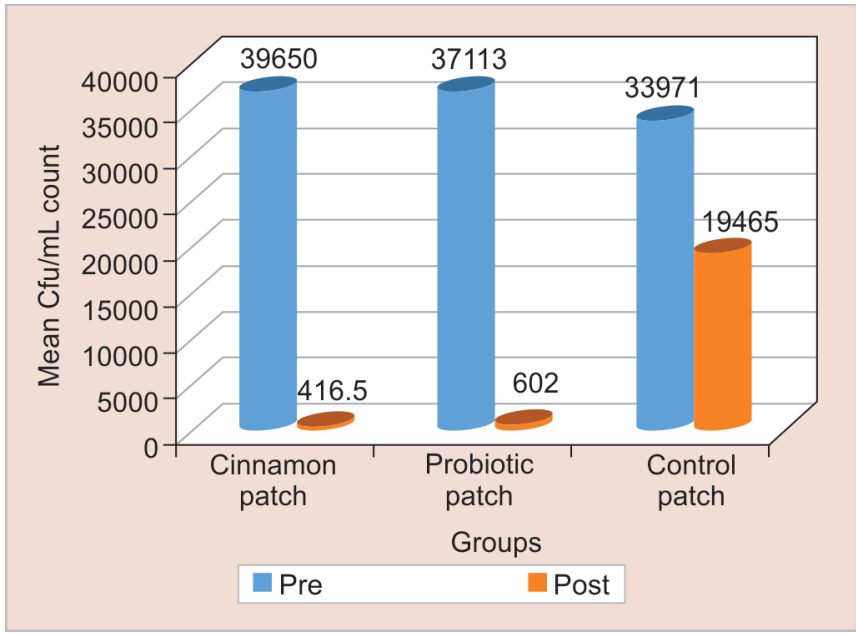

Fig. 4: Intergroup comparison of colony-forming units in the cinnamon patch group, probiotic patch group, and control patch group

displeasure in terms of taste. Five percent of the subjects in all the three groups complained of nausea on the placement of the patch. However, none of the subjects reported any difficulties with regards to alteration of breath, teeth staining, irritation, burning, or any other symptoms (Table 6).

\section{Discussion}

Streptococcus mutans has been implicated as the major causative organism in the etiology of caries. ${ }^{18,19}$ Salivary S. mutans levels are a reflection of the number of tooth sites that have been colonized as 
Table 4: One-way ANOVA

\begin{tabular}{lllllll}
\hline & & Sum of squares & $d f$ & Mean square & $F$ & Sig. \\
\hline Baseline & Between groups & 323730493.33 & 2 & 161865246.67 & 0.37 & 0.7 \\
& Within groups & 25211951400.00 & 57 & 442314936.84 & & \\
& Total & 25535681893.33 & 59 & & & \\
Post-intervention & Between groups & 4791283543.33 & 2 & 2395641771.67 & 53.3 & $0.05^{*}$ \\
& Within groups & 2561919675.00 & 57 & 44945959.211 & & \\
& Total & 753203218.33 & 59 & & & \\
\hline
\end{tabular}

${ }^{*} p$ value-significant; $p>0.05$-not significant

Table 5: Post hoc Scheffe's test

\begin{tabular}{|c|c|c|c|}
\hline \multicolumn{4}{|c|}{ Post-intervention (a) } \\
\hline \multirow[b]{2}{*}{ Group } & \multirow[b]{2}{*}{$N$} & \multicolumn{2}{|c|}{ Subset for $a=0.05$} \\
\hline & & 1 & 2 \\
\hline Cinnamon patch & 20 & 416.5000 & \\
\hline Probiotic patch & 20 & 602.0000 & \\
\hline Control patch & 20 & & $19,465.0000$ \\
\hline \multicolumn{4}{|c|}{ Change (b) } \\
\hline & & \multicolumn{2}{|c|}{ Subset for $a=0.05$} \\
\hline Group & $N$ & 1 & 2 \\
\hline Cinnamon patch & 20 & $14,506.0000$ & \\
\hline Probiotic patch & 20 & & $36,511.0000$ \\
\hline Control patch & 20 & & $39,233.5000$ \\
\hline
\end{tabular}

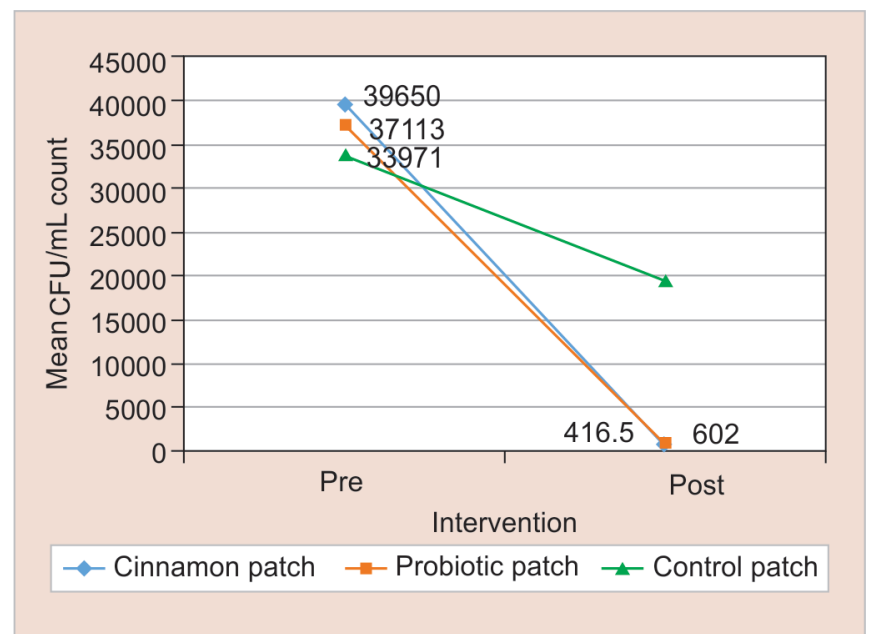

Fig. 5: Intergroup comparison of reduction in colony-forming units preand post-intervention in the cinnamon patch group, probiotic patch group, and control patch group

well as their proportion in dental plaque. ${ }^{20,21}$ A positive correlation has been quoted about the concentration of S. mutans in saliva and dental caries by Lenander-Lumikari and Loimaranta, ${ }^{21}$ Emilson, ${ }^{22}$ and Salonen et al. ${ }^{23}$ Saliva samples are most often preferred for quantification of S. mutans according to Köhler et al. ${ }^{24}$ The number of mutans streptococci in saliva can be used for the evaluation of caries risk and is also useful for monitoring the level of colonization of the individual (Krasse, 1984). ${ }^{25}$ Hence, in the present study, the salivary S. mutans levels were assessed to evaluate the anti-caries effect exhibited by three different mucoadhesive patches.

Keeping in mind the evidence of an alarming increase in the global spread of resistant clinical isolates, the need to find alternate,
Table 6: Feedback with respect to patient compliance and adverse effects

\begin{tabular}{|c|c|c|c|}
\hline Adverse effects & $\begin{array}{l}\text { Cinnamon } \\
\text { patch }\end{array}$ & Probiotic patch & $\begin{array}{l}\text { Control patch } \\
\text { (placebo) }\end{array}$ \\
\hline $\begin{array}{l}\text { Displeasure } \\
\text { in taste, teeth } \\
\text { staining, nausea, } \\
\text { burning, } \\
\text { other }\end{array}$ & $10 \%$ & & \\
\hline
\end{tabular}

newer antimicrobial agents has become of paramount importance. Also, the past record of rapid and widespread emergence of resistance to newly introduced synthetic antimicrobial agents indicates that even newer drugs might suffer the same fate. ${ }^{26}$ This has prompted researchers to study herbal products and functional foods in the hope of combating this rising tide of resistant bacteria safely and efficiently.

Among the various plants studied, Cinnamomum zeylanicum Blume (cinnamon ${ }^{4,5}$ has emerged as a potential herbal antimicrobial agent. The bark of cinnamon is one of the most important and popular spices used worldwide not only for cooking but also in traditional and modern medicine. According to the US Department of Health, the recommended safe dose is $6 \mathrm{~g}$ daily for 6 weeks or less, at this level cinnamon is considered safe. ${ }^{27}$ Although antimicrobial properties of cinnamon bark oil have been reported recently, scientific evidence on the action of cinnamon bark oil on specific pathogenic oral bacteria, particularly pathogens related to periodontal disease and dental caries, are still scarce.

Besides the medicinal plants, recently probiotics have also been recognized to affect $S$. mutans and other harmful oral and gut microflora. Grover and Luthra reported that the hypothetical mechanism of probiotic action in the oral cavity is by various direct and indirect means. ${ }^{28}$ Various indirect actions include modulation of systemic immune function, enhancement of local immunity, regulation of mucosal permeability, and its effect on the non-immunological defense mechanism. It also functions as an antioxidant and neutralizes free electrons, thus preventing plaque formation. The possible direct interactions include binding of oral microorganisms to protein, production of chemicals that inhibit oral bacteria, action on plaque formation, and its complex ecosystem by competing and intervening with bacterial attachments. ${ }^{28}$ Probiotics in the oral cavity have been used to replace cariogenic organisms like streptococci and Lactobacillus species with strains of bacteria that are not cariogenic. ${ }^{10}$ Bacterial strains that have been tested for probiotic action in the oral cavity and in vitro against oral pathogens include lactobacilli species (Lactobacillus acidophilus, L. rhamnosus GG, Lactobacillus johnsonii, Lactobacillus casei, L. rhamnosus, Lactobacillus gasseri, Lactobacillus reuter, Lactobacillus paracasei, Lactobacillus plantarum), Bifidobacterium species (Bifidobacterium bifidum, Bifidobacterium 
longum, Bifidobacterium infantis, Bifidobacterium animalis strain DN-173 010), and others (Streptococcus salivarius, Weissella cibaria). ${ }^{15}$ Clinical studies by Näse et al., ${ }^{13}$ Caglar et al., ${ }^{29}$ Haukioja et al., ${ }^{30} \mathrm{Cildir}$ et al., ${ }^{31}$ Jindal et al., ${ }^{9}$ Harini and Anegundi, ${ }^{11}$ Khanafari et al., ${ }^{14}$ Saha et al., ${ }^{32}$ and Chinnappa et al. (2013), ${ }^{33}$ have confirmed that probiotic lactobacilli can reduce the counts of $S$. mutans after ingestion of L. rhamnosus-GG, L. reuteri, L. plantarum, and lactobacilli mix of which L. rhamnosus and L. plantarum were found to have better antimicrobial efficacy against $S$. mutans $s^{9,13,14,30,32}$ and hence it was decided to use the blend of pure strains of the probiotic bacteria $L$. rhamnosus (TSP-Lrh1) and L. plantarum (TSP-LP1) for the formulation of probiotic mucoadhesive patch.

The suppression of caries causing organisms like S. mutans by local administration of chlorhexidine has been well established. The most commonly used and recommended oral health care product, chlorhexidine, also considered as a "gold standard" for oral antimicrobial agents, was among the best range of bisbiguanides synthesized ad hoc as bactericides by Davies et al. in $1954 .{ }^{34,35}$ However, the use of chlorhexidine has depleted in recent years which can be attributed to its various side effects, like brown staining of teeth, altered taste sensation, soreness of the oral mucosa after use, and most importantly, the fear of the development of resistant bacterial strains which might eventually render the product less effective. ${ }^{36}$ A study conducted by Harini and Anegundi concluded that probiotics are as effective as chlorhexidine and safer than chlorhexidine. ${ }^{11}$ Hence, in the proposed placebo-controlled study, probiotics were used as a safer alternative to chlorhexidine in children.

A mouth rinse can be an effective chemotherapeutic agent used as adjuvant to routine home care remedy to maintain oral hygiene as well as prevent dental caries by targeting the cariogenic microflora but when it comes to its use in children below 10 years, compliance is less. A mucoadhesive patch incorporated with anticariogenic and antibacterial agents may help in slowly releasing the drug in the oral cavity resulting in a constant circulation of the drug in the oral cavity through saliva; moreover, some amount of it also gets absorbed in the systemic circulation ${ }^{12}$ and eventually facilitates its permanent installation as an inherent component of the saliva enhancing its antimicrobial potential and thus can be used as an effective adjuvant to a daily oral hygiene maintenance routine. Mucoadhesive patches are commonly used in the field of dentistry as a local drug delivery vehicle for treating oral mucosal lesions, periodontal problems, and reducing dental pain. ${ }^{37-40}$ To the best of our knowledge, its potential as an alternative to mouthwash especially in pediatric patients has not been explored.

There is no documented literature on the efficacy of cinnamon bark oil incorporated and probiotic incorporated mucoadhesive patch against salivary S. mutans; hence, this placebo-controlled study with newly formulated cinnamon bark oil incorporated and probiotic incorporated mucoadhesive patch was taken up to test the hypothesis.

In the first phase, the antimicrobial efficacy and MIC of cinnamon bark oil were evaluated against a pure strain of $S$. mutans (MTCC 890). Although antimicrobial properties of cinnamon bark oil have been reported recently, scientific evidence on the action of cinnamon bark oil on specific pathogenic oral bacteria, particularly pathogens related to periodontal disease and dental caries, are still scarce. Keeping this in mind, it was decided to assess the antimicrobial efficacy and MIC of cinnamon bark oil against S. mutans. The antibacterial effect of cinnamon bark oil against
S. mutans was determined using the broth microdilution method. Minimal inhibitory concentration of the cinnamon oil was estimated to be $20 \mu \mathrm{L} / \mathrm{mL}$ and it was under the results obtained in the study conducted by Chaudhari et al. ${ }^{5}$ and Zainal-Abidin et al. ${ }^{41}$

The strength of probiotic was determined taking into consideration the literature available on the safe and effective strength of probiotic strains in children from a dental point of view which ranges from $10^{5}$ to $10^{9} \mathrm{CFU} / \mathrm{g}$ with $10^{9} \mathrm{CFU} / \mathrm{g}$ being most effective. ${ }^{13,41-45}$ As per the safety guidelines for probiotics use in children, a healthy child can safely take up to 10 billion per day. ${ }^{46,47}$ In the current study, a probiotic blend of 10 billion was used composed of 5 billion CFU/gm L. rhamnosus (TSP-Lrh1) and 5 billion CFU/gm of L. plantarum (TSP-Lp1).

A pediatric population of caries active children were chosen based on a systematic review done by Leal et al. in $2010^{48,49}$ with deft/DMFT score between 3 and 5. A study conducted by Sudha et al. ${ }^{50}$ on 5-13 years age group showed a higher prevalence of dental caries in 5-7 years age group compared with that of 8-9 and 11-13 years age group. In the present study, we have taken up children of 7-10 years as at this age the permanent teeth are erupting, so there are chances that the new surfaces would be colonized by pathogenic bacteria. Hence, preventive measures taken at this time might be helpful in the long run. Also, positive compliance could be expected from a child of this age group. According to Jean Piaget, 7 years of age largely correspond to an increase in cognitive development. Therefore, an opportunity existed and prompted us to take up the present study with an age group of 7-10 years.

The collection of saliva was done as mentioned in the study done by Westergren and Krasse. ${ }^{51}$ The microbial growth was recorded in terms of colony-forming units $/ \mathrm{mL}$. The range of colony-forming units $/ \mathrm{mL}$ of salivary S. mutans is under the findings of Jindal et al. ${ }^{9}$ The pre-intervention (baseline) $\mathrm{CFU} / \mathrm{mL}$ was in the range of $10^{4} \mathrm{CFU} / \mathrm{mL}$. The intragroup comparison of $\mathrm{CFU} / \mathrm{mL}$ from baseline to post-intervention showed a highly significant reduction ( $p=0.001)$ in salivary S. mutans counts for all three groups with CFU count reduction being less in the control group compared with the cinnamon patch group and probiotic group (Figs 4 and 5). Reduction in salivary $S$. mutans count in the cinnamon patch group was under a previous study done by Al-Joubori et al. ${ }^{52}$ wherein cinnamon extract mouth rinse was used. Clinical trials conducted using cinnamon against $S$. mutans are very scarce. The CFU count reduction seen in the probiotic patch group was under previous studies by Näse et al., ${ }^{13}$ Ahola et al., ${ }^{53}$ Jindal et al., ${ }^{9}$ and Siddiqui et al. ${ }^{3}$ wherein significant reduction was seen $S$. mutans count compared with control group $(p<0.05)$, whereas our results were in contrast to the study done by Montalto et al. ${ }^{54}$ that found an increase in lactobacilli count but $S$. mutans count remain unchanged. In all these studies, either probiotic curd or milk or cheese was used.

To the best of our knowledge, there is no documented literature on cinnamon bark oil incorporated mucoadhesive patch or probiotic incorporated mucoadhesive patch. The intergroup comparison between all three groups showed a non-significant difference at baseline indicating that baseline was well standardized (Table 4, and Figs 4 and 5). Post-intervention there was a significant mean difference in the CFU count between group I and group III and between group II and group III, whereas there was no significant mean difference in the post-intervention CFU count between group I and group II. This shows that cinnamon bark oil incorporated mucoadhesive patch and probiotic incorporated mucoadhesive patch have a comparable effect against salivary S. mutans. The 
overall percentage reduction of salivary S. mutans was more in the cinnamon patch group and probiotic patch group compared with the control patch group (Tables 3 to 5, and Figs 4 and 5). In our study, the control patch which is a placebo patch has also shown a fairly significant reduction in salivary S. mutans count post-intervention indicating some amount of antimicrobial effect of the mucoadhesive polymers used for the formulation and at the same time throughout the course of the study children followed the instructed oral hygiene maintenance protocols under the strict supervision of the examiner and the parent.

We can thus infer that both cinnamon bark oil incorporated mucoadhesive patch and probiotic incorporated mucoadhesive patch have proven to be very effective in reducing salivary $S$. mutans.

\section{Conclusion}

We can conclude that:

- Both cinnamon bark oil extract incorporated mucoadhesive patch and probiotic incorporated patch have rather strong antimicrobial property owing to its ability to cause a highly significant reduction in salivary S. mutans.

- Cinnamon bark oil incorporated mucoadhesive patch is comparable to the probiotic incorporated patch due to its similarity in the reduction of salivary S. mutans counts.

- Both the patches had good patient acceptance.

\section{Limitations of the Study}

In this placebo-controlled study, we have studied the effect of newly formulated cinnamon bark oil incorporated mucoadhesive patch and probiotic incorporated mucoadhesive patch against salivary $S$. mutans. We have not compared it with any commercially available product or gold standard as there are no mucoadhesive patches available commercially that affect caries causing bacteria to be used in the pediatric population.

\section{Future Directions of the Study}

- Further research can be done to assess the effect of mucoadhesive patches used as an alternative to mouthwash.

- Bacteriocin released by probiotics can be utilized in the future for newer formulations.

- Further studies can be done to check its efficacy to keep the oral bacterial load in check and also acceptance in special children with poorly developed motor skills and cognition and children who are chronically hospitalized or bedridden where oral hygiene maintenance becomes difficult.

\section{Acknowledgments}

Triphase Pharmaceuticals Pvt. Ltd., Mysuru, India.

\section{References}

1. Islam B, Khan S, Khan A. Dental caries: from infection to prevention. Med Sci Monit 2007;13(11):RA196-RA203.

2. Keyes PH. The infectious and transmissible nature of experimental dental caries. Findings and implications. Arch Oral Biol 1960;1(4):304320. DOI: 10.1016/0003-9969(60)90091-1.

3. Siddiqui M, Singh C, Masih U, et al. Evaluation of Streptococcus mutans levels in saliva before and after consumption of probiotic milk: a clinical study. J Int Oral Health 2016;8(2):195-198.
4. Unlu M, Ergene E, Unlu GV, et al. Composition, antimicrobial activity and in vitro cytotoxicity of essential oil from Cinnamomum zeylanicum Blume (Lauraceae). Food Chem Toxicol 2010;48(11):3274-3280. DOI: 10.1016/j.fct.2010.09.001.

5. Chaudhari LK, Jawale BA, Sharma S, et al. Antimicrobial activity of commercially available essential oils against Streptococcus mutans. J Contemp Dent Pract 2012;13(1):71-74. DOI: 10.5005/ jp-journals-10024-1098.

6. Wendakoon CN, Sakaguchi M. Inhibition of amino acid decarboxylase activity of Enterobacter aerogenes by active components of spices. J Food Prot 1995;58(3):280-283. DOI: 10.4315/0362-028X-58.3.280.

7. Ramos-Nino ME, Cliford MN, Adams MR. Quantitative structure activity relationship for the effect of benzoic acid, cinnamic acids and benzaldehydes on listeria monocytogenes. J Appl Microbiol 1996;80:303-310.

8. Tandon V, Arora V, Yadav V, et al. Concept of probiotics in dentistry. Int J Dent Med Res 2015;1(6):206-209.

9. Jindal G, Pandey RK, Agarwal J, et al. A comparative evaluation of probiotics on salivary mutans streptococci counts in Indian children. Eur Arch Paediatr Dent 2011;12(4):211-215. DOI: 10.1007/BF03262809.

10. Narwal A. Probiotics in dentistry - A review. J Nutrit Food Sci 2011;1(05):5. DOI: 10.4172/2155-9600.1000114.

11. Harini PM, Anegundi RT. Efficacy of a probiotic and chlohexidine mouth rinses: a short-term clinical study. J Indian Soc Pedodont Prevent Dentis 2010;28(3):179-182. DOI: 10.4103/0970-4388.73799.

12. Ahanthem N, Basavaraju SM, Pachipulusu B, et al. Orodental local drug delivery. J Health Sci Res 2015;6(2):41-46. DOI: 10.5005/ jp-journals-10042-1019.

13. Näse L, Hatakka K, Savilahti E, et al. Effect of long-term consumption of a probiotic bacterium, lactobacillus rhamnosus $\mathrm{GG}$, in milk on dental caries and caries risk in children. Caries Res 2001;35(6):412-420. DOI: 10.1159/000047484.

14. Khanafari A, Porgham SH, Ebrahimi MT. Investigation of probiotic chocolate effect on streptococcus mutans growth inhibition. Jundishapur J Microbil 2012(4):590-597. DOI: 10.5812/jjm.3861.

15. Bhalla $M$, Ingle NA, Kaur N, et al. Mutans streptococci estimation in saliva before and after consumption of probiotic curd among school children. J Int Soc Prev Community Dent 2015;5(1):31-34. DOI: 10.4103/2231-0762.151970.

16. Ulreich S. Solvent cast technology - a versatile tool for thin film production. Progr Colloid Polym Sci 2005;130:1-14.

17. Novak GD. Generally regarded as safe. Ocul Surf 2017;15(1):152-155. DOI: $10.1016 /$ j.jtos.2016.11.002.

18. Loesche WJ. Role of Streptococcus mutans in human dental decay Microbiol Rev 1986;50(4):353-380. DOI: 10.1128/MMBR.50.4.353380.1986.

19. Hamada S, Slade HD. Biology, immunology, and cariogenicity of Streptococcus mutans. Microbiol Rev 1980;44(2):331-384. DOI: 10.1128/ MMBR.44.2.331-384.1980.

20. Togelius J, Kristoffersson K, Anderson $\mathrm{H}$, et al. Streptococcus mutans in saliva: intraindividual variations and relation to the number of colonized sites. Acta Odontol Scand 1984;42(3):157-163. DOI: 10.3109/00016358408993867.

21. Lenander-Lumikari M, Loimaranta V. Saliva and dental caries. Adv Dent Res 2000;14(1):40-47. DOI: 10.1177/08959374000140010601.

22. Emilson CG. Prevalence of Streptococcus mutans with different colonial morphologies in human plaque and saliva. Scand J Dent Res 1983;91(1):26-32. DOI: 10.1111/j.1600-0722.1983.tb00771.x.

23. Salonen $\mathrm{L}$, Allander $\mathrm{L}$, Bratthall $\mathrm{D}$, et al. Mutans streptococci, oral hygiene, and caries in an adult Swedish population. J Dent Res 1990;69(8):1469-1475. DOI: 10.1177/00220345900690080401.

24. Köhler B, Pettersson BM, Bratthall D. Streptococcus mutans in plaque and saliva and the development of caries. Scand J Dent Res 1981;89(1):19-25. DOI: 10.1111/j.1600-0722.1981.tb01273.x.

25. Krasse B. Can microbiological knowledge be applied in dental practice for the treatment and prevention of dental caries. J Can Dent Assoc 1984;50(3):221-223. 
26. Khan R, Islam B, Akram M, et al. Antimicrobial activity of five extracts against multi drug resistant (MDR) strains of bacteria and fungus of clinical origin. Molecules 2009;14(2):586-597. DOI: 10.3390/ molecules 14020586.

27. U.S. Department of Health. Using Dietry Supplements Wisely. nccam. nih.gov/health/supplements/wiseuse.htm.

28. Grover HS, Luthra S. Probiotics: the nano soldiers of oral health. J Indian Acad Clin Med 2011;13(1):s48-s54.

29. Caglar E, Sandalli N, Twetman S, et al. Effect of yogurt with Bifidobacterium DN-173 010 on salivary mutans streptococci and lactobacilli in young adults. Acta Odontol Scand 2005;63(6):317-320. DOI: 10.1080/00016350510020070.

30. Haukioja A, Yli-Knuuttila H, Loimaranta V, et al. Oral adhesion and survival of probiotic and other lactobacilli and bifidobacteria in vitro. Oral Microbiol Immunol 2006;21(5):326-332. DOI: 10.1111/j.1399302X.2006.00299.x.

31. Cildir SK, Germec D, Sandalli N, et al. Reduction of salivary mutans streptococci in orthodontic patients during daily consumption of yoghurt containing probiotic bacteria. Eur J Orthod 2009;31(4): 407-411. DOI: 10.1093/ejo/cjn108.

32. Saha S, Tomaro-Duchesneau C, Malhotra M, et al. Suppression of Streptococcus mutans and Candida albicans by probiotics: an in vitro study. Dentistry 2:141. DOI: 2012.10.4;172/216;1-1122.1000141.

33. Chinnappa A,Konde S, Raj S, et al. Probiotics for future caries control: a short-term clinical study. Indian J Dent Res 2013;24:547-549.

34. Davies GE, Francis J, Martin AR, et al. 1:6-Di-4'- chloropjhenyldiguanidohexane (hibitane); laboratory invrestigation of a new antibacterial agent of high potency. Br J Pharmacol Chemother 954;9(2);192-196.

35. Hennessey TD. Some antimicrobial properties of chlorhexidine. J Periodont 1973;12:61-67.

36. Järvinen $\mathrm{H}$, Tenovuo J, Huovinen P. In vitro susceptibility of Streptococcus mutans to chlorhexidine and six other antimicrobial agents. Antimicrob Agents Chemother 1993;37(5):1158-1159. DOI: 10.1128/AAC.37.5.1158.

37. Shehab LA, Basheer B, Baroudi K. Effectiveness of lidocaine denti patch system versus lidocaine gel as topical anaesthetic agent in children. J Indian Prev Dent 2015;33(4):285-290. DOI: 10.4103/09704388.165664

38. Annigeri RG, Jadhav M, Juturu T. Clinical evaluation of transmucosal mucoadhesive meloxicam patch in dental pain reduction: a preliminary study. Indian J Pain 2015;29(2):82-85. DOI: 10.4103/09705333.155174 .

39. Obaidat RM, Bader A, Al-Rajab W, et al. Preparation of mucoadhesive oral patches containing tetracycline hydrochloride and carvacrol for treatment of local mouth bacterial infections and candidiasis. Sci Pharm 2011;79(1):197-212. DOI: 10.3797/scipharm.1004-18.
40. Vogue. C, Authentic premium Ceylon Cinnamon from Sri Lanka. Website: https://www.cinnamonvogue.com.

41. Zainal-Abidin Z, Mohd-Said S, Abdul Majid FA, et al. Anti-bacterial activity of cinnamon oil on oral pathogens. Open Confer Proceed J 2013:4(2):12-16. DOI: 10.2174/2210289201304020012.

42. Al-Duboni G, Osman MT, Al-Naggar R. Antimicrobial activity of aqueous extracts of cinnamon and ginger on two oral pathogens causing dental caries. RJPBCS 2013;4(3):957-965.

43. Varalakshmi B, Vijaya Anand A, Karpagam T, et al. In vitro antimicrobial and anticancer activity of Cinnamomum zeylanicum Linn bark extracts. Int J Pharm Pharm Sci 2014;6(1):12-18.

44. Rao PV, Gan SH. Cinnamon: a multifaceted medicinal plant. Evidence-Based Complement Alternat Med 2014. 1-12. DOI: $10.1155 / 2014 / 642942$.

45. Dhanya Kumar NM, Sidhu P. The antimicrobial activity of Azardirachta indica, Glycyrrhiza glabra, Cinnamum zeylanicum, Syzygium aromaticum: Accacia nilotica on Streptococcus mutans and Enterococcus faecalis - an in vitro study. Endodontology 2011;23: $18-25$.

46. Arora M, Baldi A. Regulatory categories of probiotics across the globe: a review representing existing and recommended categorization. Indian J Med Microbiol 2015;33(5):2-10. DOI: 10.4103/02550857.150868.

47. Kligler B, Hanaway $P$, Cohrrsen A. Probiotics in children. Pediatr Clin North Am 2007;54(6):949-967. DOI: 10.1016/j.pcl.2007.10.002.

48. Leal SC and Mickenautsch S. Salivary streptococcus mutans count and caries outcome-a systematic review. J Minim Interv Dent 2010;3(4):137-147.

49. Gupta C, Kumari A, Garg AP, et al. Comparative study of cinnamon oil and clove oil on some oral microbiota. Acta Biomed 2011;82: 197-199.

50. Sudha P, Bhasin S, Anegundi RT. Prevalence of dental caries among 5-13-year-old children of Mangalore city. J Indian Soc Pedod Prev Dent 2005;23(2):74-79. DOI: 10.4103/0970-4388.16446.

51. Westergren G, Krasse B. Evaluation of a micro method for determination of Streptococcus mutans and Lactobacillus infection. J Clin Microbiol 1978;7(1):82-83.

52. Shaymaa Al-Joubori K, Al-Obaidi WA. Effect of cinnamon extracts on streptococci and mutans streptococci in comparison to chlorhexidine gluconate. J Baghdad Colle Dentis 2017;23(1):141-145.

53. Ahola AJ, Yli-Knuuttila $H$, Suomalainen $T$, et al. Short term consumption of probiotic-containing cheese and its effect on dental caries risk factors. Arch Oral Biol 2002;47(11):799-804. DOI: 10.1016/ S0003-9969(02)00112-7.

54. Montalto $\mathrm{M}$, Vastola $\mathrm{M}$, Marigo $\mathrm{L}$, et al. Probiotic treatment increases salivary counts of lactobacilli: a double-blind, randomized, controlled study. Digestion 2004;69(1):53-56. DOI: 10.1159/000076559. 